\title{
FOETAL HEART RATE IN FIRST TRIMESTER THREATENED ABORTION FOR PREDICTING PREGNANCY OUTCOME
}

\author{
Rajat Kumar Ray1, Sunita Samal² \\ ${ }_{1}^{1}$ Director, Ray Hospital and Test Tube Baby Centre. \\ ${ }^{2}$ Consultant, Ray Hospital and Test Tube Baby Centre.
}

\section{ABSTRACT}

\section{BACKGROUND}

To manage a case of first trimester bleeding with slow foetal heart rate, prognosis and planning are necessary.

Aims- To study the relationship of Foetal Heart Rate (FHR) in first trimester threatened abortion and pregnancy outcome.

\section{MATERIALS AND METHODS}

This was a prospective study of 86 women presented to Ray Hospital and Test Tube Baby Centre, Rourkela, India with vaginal bleeding in first trimester between 1st January 2015 and 31st May 2016. All women were subjected to ultrasound examination to confirm viability of embryo and foetal heart rate. The pregnancies were followed and pregnancy outcomes were recorded.

Statistical Analysis- Statistical analysis was done by computing several measures of diagnostic performance like sensitivity, specificity, positive and negative predictive values using MedCalc statistical software.

\section{RESULTS}

17 women out of 86 women had spontaneous abortion. We found a cut-off value of FHR $<120 /$ minute as the best in predicting pregnancy outcome.

\section{CONCLUSION}

Women with first trimester threatened abortion are at increased risk of pregnancy loss when FHR is $<120 /$ minute.

\section{KEYWORDS}

FHR, Threatened Abortion, Live Birth.

HOW TO CITE THIS ARTICLE: Ray RK, Samal S. Foetal heart rate in first trimester threatened abortion for predicting pregnancy outcome. J. Evolution Med. Dent. Sci. 2017;6(35):2921-2923, DOI: 10.14260/Jemds/2017/629

\section{BACKGROUND}

Vaginal bleeding is a common first trimester complication, often considered to be a sign of a problem in pregnancy. Bleeding has been related to miscarriage, preterm birth, low birth weight and small-for-gestational age infants. The term threatened abortion is used to describe women who have uterine bleeding in the presence of a closed cervix and sonographic visualisation of an intrauterine pregnancy with detectable foetal cardiac activity during the first 20 weeks of pregnancy. The term "threatened" is used to describe these cases, because miscarriage does not always follow uterine bleeding in early pregnancy, even after repeated episodes or large amounts of bleeding. In fact, a greater percentage of pregnancies with both foetal cardiac activity and vaginal bleeding at 7 to 11 weeks of gestation do not miscarry; the higher success rate is associated with bleeding at the later end of the gestational age range.

Transvaginal ultrasonography is the cornerstone of the evaluation of bleeding in early pregnancy. It is most useful in bleeding patients with a positive pregnancy test in whom an intrauterine pregnancy has not been previously confirmed by

Financial or Other, Competing Interest: None.

Submission 11-04-2017, Peer Review 23-04-2017,

Acceptance 27-04-2017, Published 01-05-2017.

Corresponding Author:

Dr. Rajat Kumar Ray,

Ray Hospital and Test Tube Baby Centre,

N-18, Civil Township,

Rourkela-769004, India.

E-mail: rajatkuray@gmail.com

DOI: $10.14260 /$ jemds $/ 2017 / 629$

(c) (i) $\$$ imaging studies. In these women, ultrasound examination is performed to determine whether the pregnancy is intrauterine or extrauterine (Ectopic), and if intrauterine whether the pregnancy is viable (Foetal cardiac activity present) or nonviable.

Foetal heart activity is the earliest proof of a viable pregnancy and it has been documented in utero by Transvaginal Sonography (TVS) as early as 36 days' menstrual age, approximately at the time when the heart tube starts to beat.(1) This embryonic marker may often precede the visualisation of embryo itself and can serve as the basis for confirmation of a living embryo.

Cardiac activity should be evident when the embryo is over $2 \mathrm{~mm}$.(2) However, in 5\% - 10\% of embryos between 2 and $4 \mathrm{~mm}$ it cannot be demonstrated, although the corresponding pregnancies will have a normal outcome. $(3,4)$ With increasing gestational age, there is an increase in FHR. From 5 to 9 weeks of gestation, there is a rapid increase in the mean heart rate from $110 /$ minute to $175 /$ minute. The heart rate then gradually decreases to around 160 /minute to 170/minute. Abnormal developmental pattern of FHR and/or bradycardia has been associated with subsequent miscarriage. A single observation of an abnormally slow heart rate does not necessarily indicate subsequent embryonic death, but a continuous decline of embryonic heart activity might inevitably be associated with miscarriage. The risk of pregnancy loss increases as FHR decreases, especially between 6 to 9 weeks.

Aneuploidy has been linked to abnormal FHR. Foetuses with trisomy 21, trisomy 13 and Turner syndrome have a greater probability of an increased FHR $>2$ standard 
deviations above the mean, whereas foetuses with trisomy 18 and triploidy have a greater probability of a decreased FHR of $<2$ standard deviations below the mean.

Several authors have evaluated the relationship of slow FHR in early pregnancy and pregnancy outcome. $(5,6,7,8,9)$ However, most of them have taken into account normal pregnant women without any complications. So we decided to study the relationship between FHR and pregnancy outcome in patients with threatened abortion.

\section{MATERIALS AND METHODS}

This was a prospective study of 86 women presented to Ray Hospital and Test Tube Baby Centre, Rourkela, India with vaginal bleeding in first trimester between 1st January 2015 and 31st May 2016. The purpose of this study was explained in detail to all women recruited and all of them agreed to cooperate. Written informed consent was obtained from all participants.

\section{The following Subjects were included in the Study}

a. Singleton pregnancy,

b. Gestational age of 6-12 weeks,

c. History of vaginal bleeding or spotting in preceding 24 hours,

d. Living embryo demonstrating cardiac activity on TVS.

\section{Exclusion Criteria were as follows}

a. Any uterine pathology such as myomas or malformations,

b. Loss to follow-up, and

c. A vaginal or cervical lesion visualised on clinical examination that could explain the vaginal bleeding.

All patients were subjected to per vaginum and per speculum examinations. It was followed by a TVS using Wipro GE Voluson P8 machine. The TVS probe was inserted gently into the vagina, and the uterus and adnexal regions were scanned. The intrauterine gestational sac, embryo and its cardiac activity were identified. Crown Rump Length (CRL) was measured to confirm Gestational Age (GA). In pregnancies at $<7$ weeks' gestation, the embryonic crown and rump cannot be visualised and therefore the CRL was measured as the greatest length of the embryo. From 7 weeks onwards, the CRL was measured in a sagittal section of the embryo with care being taken to avoid inclusion of the yolk sac.

If there was a discrepancy of $>5$ days between gestational age calculated by ultrasound and last menstrual period, then GA calculated by CRL was considered accurate. After embryo vitality was confirmed, the foetal heart rate was measured by M-mode in all cases. The FHR was calculated as beats per minute by the software of the ultrasound machine after measurement by electronic calipers of the distance between two heart waves on a frozen M-mode image. The heart rate was then recorded and used for statistical analysis.

The pregnancies were followed and pregnancy outcomes were recorded. Delivery before 28 weeks was considered abortion, whereas delivery of a live foetus beyond 28 weeks was considered a live birth.

\section{Statistical Analysis}

Statistical analysis was done by computing several measures of diagnostic performance like sensitivity, specificity, positive and negative predictive values using MedCalc statistical software.

\section{RESULTS}

86 women were recruited to this study. The mean maternal age was $28.84 \pm 4.02$ years (range, 22 - 39 years). The mean gestational age was $9.02 \pm 1.52$ weeks (range, $7-12$ weeks). The mean foetal heart rate was $158.7 \pm 31.6 \mathrm{bpm}$ (range, 76 $190 \mathrm{bpm})$.

17 women out of 86 women had spontaneous abortions. Out of these, 14 cases ( $82.4 \%$ ) had spontaneous abortion before 12 weeks of pregnancy. All cases aborted latest by 20 weeks GA. No anomaly could be detected with all the 69 live births. Out of 69 cases, 6 cases $(8.7 \%)$ had preterm delivery.

Table 1 depicts the distribution of FHR to predict pregnancy outcome. The sensitivity, specificity, positive and negative predictive values of FHR $<120 /$ minute for predicting pregnancy outcome were respectively $70.6 \%$, $94.2 \%, 75 \%$ and $92.9 \%$.

\begin{tabular}{|c|c|c|c|c|}
\hline $\begin{array}{c}\text { Cut-Off } \\
\text { Point of } \\
\text { FHR } \\
\text { (Per min.) }\end{array}$ & $\begin{array}{c}\text { Sensitivity } \\
\text { (\%) }\end{array}$ & $\begin{array}{c}\text { Specificity } \\
(\%)\end{array}$ & \begin{tabular}{|c} 
Positive \\
Predictive \\
Value (\%)
\end{tabular} & $\begin{array}{l}\text { Negative } \\
\text { Predictive } \\
\text { Value (\%) }\end{array}$ \\
\hline 90 & 11.8 & 100 & 100 & 82 \\
\hline 95 & 17.6 & 100 & 100 & 83.1 \\
\hline 100 & 23.5 & 98.5 & 80 & 84 \\
\hline 105 & 47.1 & 97.1 & 80 & 88.1 \\
\hline 110 & 52.9 & 95.7 & 75 & 89.2 \\
\hline 115 & 58.8 & 94.2 & 71.4 & 90.2 \\
\hline 120 & 70.6 & 94.2 & 75 & 92.9 \\
\hline 125 & 70.6 & 88.4 & 60 & 95.4 \\
\hline 130 & 70.6 & 87 & 57.1 & 92.3 \\
\hline 135 & 70.6 & 84.1 & 52.2 & 92.1 \\
\hline 140 & 70.6 & 78.3 & \begin{tabular}{|l|}
44.4 \\
\end{tabular} & 91.5 \\
\hline \multicolumn{5}{|c|}{ Table 1. FHR for predicting Pregnancy Outcome } \\
\hline
\end{tabular}

\section{DISCUSSION}

Women with missed periods many a time present with spotting or bleeding per vaginum. TVS plays a major role in evaluating women with threatened abortion by distinguishing living from non-living gestation. This remains one of the most common applications of ultrasound in first trimester.

FHR of $<90 /$ minute in embryos $<8$ weeks is associated with an $80 \%$ rate of embryonic demise, ${ }^{(10)}$ whereas FHR of $<70$ /minute is associated with $100 \%$ embryonic demise.(7)

Several studies have evaluated the uteroplacental circulation in patients with first-trimester threatened abortion with a live embryo. In such cases, information regarding the uteroplacental circulation obtained with the use of colour Doppler ultrasound can provide prognostic information. The investigators found that there was no alteration in the uteroplacental circulation in patients with first-trimester threatened abortion with a live embryo or that the speculated vascular injury is so minimal that it cannot be detected by Doppler ultrasound. The use of transvaginal colour Doppler ultrasound is not helpful for predicting pregnancy outcome in these cases.(10) 
Because there is an increased risk of miscarriage in foetuses with slower heart rates consideration should be given to a followup ultrasound examination, if the FHR is less than the lower limits of normal for a given GA. ${ }^{11}$

In our study, most of miscarriages took place before 12 weeks GA. The results of our study confirm that foetal demise tends to occur well before the end of the first trimester; in our study $82.4 \%$ had spontaneous abortion before 12 weeks of gestation and only $17.6 \%$ had spontaneous abortion in the second trimester. This finding is similar to a study by $\mathrm{N}$ Mohamed et al 2011.(12) The normally slower heart rate may be due to immaturity of the sinoatrial node early on or the atrial pacemaker may actually be slower in early gestation.(13) The mechanism of the slow foetal heart rate is unclear, but may represent idioventricular rates of the abnormal heart.(10)

Our study found an FHR of $<120 /$ minute with a history of bleeding per vaginum is associated with high likelihood of pregnancy loss. The sensitivity, specificity, positive and negative predictive values and accuracy of FHR $<120 /$ minute for predicting pregnancy outcome were respectively $70.6 \%$, $94.2 \%, 75 \%, 92.9 \%$ and $89.5 \%$.

This was the best cut-off point for prediction of pregnancy outcome.

So it is advisable that in a patient of threatened abortion, when the FHR is $<120$ /minute, a 1 - 2 week followup by ultrasound should be obtained. If the follow-up scan demonstrates no live embryo or foetus, the diagnosis of pregnancy demise is established. If the followup US scan demonstrated continued slow cardiac activity, further scans are warranted. If demise does occur, it is advantageous to make the diagnosis quickly to avoid the occurrence of vaginal bleeding at an inconvenient time and place and to minimise the period of concern and uncertainly for the parents. If the foetus is still alive beyond 12 weeks GA, the parents should be told that the likelihood of subsequent death is now low.

\section{CONCLUSION}

Patients with first trimester threatened abortion are at increased risk of pregnancy loss when FHR is $<120$ /minute. But if it survives the first trimester, the likelihood of subsequent death is low.

\section{REFERENCES}

[1] Tezuka N, Sato S, Kanasugi H, et al. Embryonic heart rates: development in early first trimester and clinical evaluation. Gynecol Obstet Invest 1991;32(4): 210-2.

[2] Levi CS, Lyons EA, Zheng XH, et al. Endovaginal US: demonstration of cardiac activity in embryos of less than $5.0 \mathrm{~mm}$ in crown-rump length. Radiology 1990;176(1):71-4.

[3] Goldstein SR. Significance of cardiac activity on endovaginal ultrasound in very early embryos. Obstet Gynecol 1992;80(4):670-2.

[4] Brown DL, Emerson DS, Felker RE, et al. Diagnosis of early embryonic demise by endovaginal sonography. J Ultrasound Med 1990;9(11):631-6.

[5] May DA, Sturtevant NV. Embryonal heart rate as a predictor of pregnancy outcome: a prospective analysis. J Ultrasound Med 1991;10(10):591-3.

[6] Achiron R, Tadmor 0, Mashiach S. Heart rate as a predictor of first-trimester spontaneous abortion after ultrasound proven viability. Obstet Gynecol 1991;78(3 Pt 1):330-4.

[7] Benson CB, Doubilet PM. Slow embryonic heart rate in early first trimester: indicator of poor pregnancy outcome. Radiology 1994;192(2):343-4.

[8] Doubilet PM, Benson CB. Embryonic heart rate in the early first trimester: what rate is normal? J Ultrasound Med 1995;14(6):431-4.

[9] Coulam CB, Britten S, Soenksen DM. Early (34-56 days from last menstrual period) ultrasonographic measurements in normal pregnancies. Hum Reprod 1996;11(8):1771-4.

[10] Laboda LA, Estroff JA, Benacerraf BR. First trimester bradycardia. A sign of impeding fetal loss. J Ultrasound Med 1989;8(10):561-3.

[11] Pai M. Interpreting diagnostic evidence: fundamental principles. Indian Journal of Medical Ultrasound 2004;2:79-84.

[12] Mohamed NH, Shiry E. Embryonic Heart Rate correlation with pregnancy outcome in women with first trimester bleeding. The Egyptian Journal of Hospital Medicine 2011;45:561-9.

[13] Shenker L, Astle C, Reed K, et al. Embryonic heart rates before the seventh week of pregnancy. J Reprod Med 1986;31(5):333-5. 